\title{
Screening for sexually transmitted diseases in an HIV testing clinic; uptake and prevalence
}

Epidemiology

\author{
S Madge, J Elford, M C I Lipman, J Mintz, M A Johnson
}

\author{
Department of \\ Thoracic Medicine \\ $S$ Madge \\ M C I Lipman \\ J Mintz \\ M A Johnson \\ Department of \\ Primary Care and \\ Population Sciences, \\ Royal Free Hospital \\ School of Medicine, \\ Pond Street, \\ Hampstead, London \\ NW3 2QG, UK \\ $\mathrm{J}$ Elford \\ Correspondence to: \\ Dr S Madge. \\ Accepted for publication \\ 10 July 1996
}

Objective: To estimate the prevalence of sexually transmitted diseases (STDs) and the acceptability of STD screening among people seeking an HIV antibody test in an established free standing HIV testing clinic.

Design: A 9 month period prevalence study conducted between August 1993 and April 1994.

Setting: The Same Day Testing Clinic (SDTC) for HIV antibodies at the Royal Free Hampstead NHS Trust Hospital, London.

Subjects: 242 males and 160 females attending the Same Day Testing Clinic.

Outcome measures: The prevalence of STDs including gonorrhoea, chlamydia, syphilis and hepatitis B and the percentage of clinic attenders accepting an STD screen.

Results: Of those invited to take part in the study $69 \%$ of the males $(242 / 350)$ and $59 \%$ $(160 / 269)$ of the females agreed to be screened although for a variety of reasons not everyone agreed to a full screen. Two cases of untreated syphilis, no cases of gonorrhoea and six cases of chlamydia were detected. Four people had active, previously undiagnosed herpes while three had genital warts. Evidence of previously unknown hepatitis B infection was found in 26 people. Despite a high level of previous contact with genitourinary medicine services, uptake of hepatitis $B$ vaccination among those homosexual men eligible for immunisation was low $(28 \% ; 23 / 83)$. Nine (4\%) of the males, but none of the females screened for STD were found to be HIV antibody positive.

Conclusion: Among people seeking an HIV antibody test in an established free standing HIV testing clinic, the prevalence of acute STDs was low. However, evidence of previously undiagnosed hepatitis $B$ infection was found in a number of subjects and uptake of vaccination among those most at risk had been low. While opportunistic screening for STD was acceptable to almost two thirds of HIV testing clinic attenders, a substantial minority nonetheless declined this offer. Selective STD screening could be offered to those people seeking an HIV test who report never having been screened before, as both cases of positive syphilis serology and all those of chlamydia were in people who had not previously been screened. All those at risk for hepatitis B infection should be encouraged to establish their infection status and be immunised where appropriate.

(Genitourin Med 1996;72:347-351)

Keywords: HIV; screening

\section{Introduction}

Testing an individual for HIV antibodies is an essential component in the public health efforts to reduce the spread of HIV infection not only by identifying those infected but by promoting discussion around prevention and safer sex practices.

A stated aim of the UK Government's Health of the Nation ${ }^{1}$ is a reduction in the spread of HIV and other sexually transmitted diseases (STDs). ${ }^{2}$ Historically, largely for reasons of confidentiality most testing for HIV infection took place in genitourinary clinics where an "at risk" population being screened for other STDs could be easily reached. The increase in heterosexually acquired $\mathrm{HIV}^{3}$ has increased the demand for HIV testing, and prevention issues now necessitate discussion about HIV testing in a variety of settings eg: antenatal clinics, outpatient departments, general practice. ${ }^{45}$ In such settings it may not always be possible to offer routine screening for other STDs at the time of HIV testing. Concern has been expressed that testing for HIV alone may result in STDs remaining undetected.
The UK Department of Health funded a study on the acceptability of STD screening and the prevalence of STDs among people attending the Royal Free Hospital Same Day HIV Testing Clinic. Here people are not normally offered routine STD screening although sexual health matters are routinely discussed and referrals made to the genitourinary clinic.

\section{Methods}

The Same Day Testing Clinic provides HIV antibody testing three days a week. The organisation of this clinic has been described previously. ${ }^{6}$ People initially make their appointment by telephone. On the day of the appointment each person is seen individually for pre-test counselling after which blood is taken for the HIV antibody test. Test results, accompanied by post-test counselling, are given at $4.00 \mathrm{pm}$ on the same day. Those testing positive for HIV antibodies are seen by a doctor and a counsellor and additional blood samples are taken for confirmatory tests.

Between August 1993 and April 1994 all clinic attenders were asked to complete a con- 
fidential questionnaire on arrival concerning their risk for HIV infection, their sociodemographic background and history of previous STD. Prior to the start of two out of three clinics each week patients were selected at random from clinic lists to be offered an STD screen by a doctor with genitourinary medicine training $(\mathrm{SM})$. After pre-test counselling, but before blood was taken, those patients who had been selected for the study and who agreed to participate were examined for STDs by means of a "modified" screen. As part of the screen the doctor recorded the subject's self-reported history of STD and condom use. The screening tests offered were:

- Amies swab for gonorrhoea from urethra in men and throat and rectal swab in homosexual men.

- Urethral ELISA for chlamydia in men.

- High vaginal swab in Bushby's medium for Trichomonas vaginalis and candida in women.

- Amies swab from the endocervix in women for gonorrhoea.

- Endocervical swab for chlamydia ELISA.

- Both men and women were offered additional serological tests for syphilis (TPHA, VDRL) and hepatitis B. The Amies swabs for gonorrhoea were taken in person immediately to the main microbiology laboratory that morning for plating into NYC medium. The Phadeback Chlamydia ELISA test kit was used.

Blood samples for serological tests for syphilis and hepatitis B were taken at the end of the session when blood was being taken for the HIV antibody test.

Some of the screening tests offered were not acceptable to all those who participated in the study. Consequently, the number of people on whom tests were performed varied according to the acceptability of the individual tests. Five results were not available owing to laboratory error.
Those screened telephoned in person for STD results a week later. Anyone with an obvious STD at the time of screening was referred immediately that day to the hospital genitourinary clinic and anyone with a positive result from screening was also referred for treatment, contact tracing and follow up. Most people were referred to the Royal Free genitourinary clinic via a health advisor but if a more local clinic was more convenient an appointment was arranged as soon as possible. Anyone with positive swab or serology results had the initial result discussed with them by telephone and could contact SM for further advice subsequently. Owing to the confidential nature of genitourinary clinics no further data on outcome or success of contact tracing were available.

Subjects were classified according to their risk for HIV infection as discussed with the counsellor prior to the HIV test. Some subjects subsequently disclosed additional risks to the doctor examining them for STD but for consistency remained in their initial exposure category.

\section{Results}

During the study period 2282 clinic attenders completed the confidential questionnaire. Of these, 619 were selected for STD screening of whom $402(64.9 \%)$ agreed to participate while $217(35 \cdot 1 \%)$ declined the invitation. A higher proportion of female clinic attenders were invited to participate than males, to ensure an adequate representation of females in the study.

Table 1 shows the demographic and risk profile of all those attending the SDTC between August 1993 and April 1994 who completed a questionnaire. Subjects have been divided into those invited for STD screen (242 males/160 females) who participated in the study, those invited for an STD screen who

Table 1 Demographic and risk profile of people attending the Same Day Testing Clinic, August 1993-April 1994

\begin{tabular}{|c|c|c|c|c|c|c|}
\hline & \multicolumn{4}{|c|}{ Invited for STD screen } & & \\
\hline & \multicolumn{2}{|c|}{ Accepted invitation } & \multicolumn{2}{|c|}{ Declined invitation } & \multicolumn{2}{|l|}{ Not invited } \\
\hline & $\begin{array}{l}\text { Male } \\
\text { No (\%) }\end{array}$ & $\begin{array}{l}\text { Female } \\
\text { No (\%) }\end{array}$ & $\begin{array}{l}\text { Male } \\
\text { No (\%) }\end{array}$ & $\begin{array}{l}\text { Female } \\
\text { No (\%) }\end{array}$ & $\begin{array}{l}\text { Male } \\
\text { No (\%) }\end{array}$ & $\begin{array}{l}\text { Female } \\
\text { No (\%) }\end{array}$ \\
\hline $\begin{array}{l}\text { Total } \\
\text { HIV positive }\end{array}$ & $\begin{array}{l}242(100) \\
\quad 9(4)\end{array}$ & $\begin{array}{l}160(100) \\
-(-)\end{array}$ & $\begin{array}{l}108(100) \\
2(2)\end{array}$ & $\begin{array}{l}109(100) \\
2(2)\end{array}$ & $\begin{array}{c}1113(100) \\
42(4)\end{array}$ & $\begin{array}{l}550(100) \\
\quad 6(1)\end{array}$ \\
\hline $\begin{array}{l}\text { Residence* } \\
\text { Camden \& Islington }\end{array}$ & & & & & & \\
\hline $\begin{array}{l}\text { Health Authority } \\
\text { Other London } \\
\text { Rest of UK } \\
\text { Abroad }\end{array}$ & $\begin{array}{l}91(42) \\
96(44) \\
31(14) \\
1(-)\end{array}$ & $\begin{array}{l}71(48) \\
53(36) \\
26(16) \\
-(-)\end{array}$ & $\begin{array}{l}41(40) \\
47(45) \\
15(15) \\
-(-)\end{array}$ & $\begin{array}{l}55(52) \\
33(32) \\
17(16) \\
-(-)\end{array}$ & $\begin{array}{l}417(40) \\
451(43) \\
164(16) \\
11(1)\end{array}$ & $\begin{array}{r}245(48) \\
195(39) \\
68(13) \\
-(-)\end{array}$ \\
\hline Employment ${ }^{\star}$ & & & & & & \\
\hline $\begin{array}{l}\text { Full time } \\
\text { Part time } \\
\text { Unemployed } \\
\text { Student } \\
\text { Risk for HIV }\end{array}$ & $\begin{array}{c}125(63) \\
9(5) \\
40(20) \\
24(12)\end{array}$ & $\begin{aligned} & 62(53) \\
& 9(8) \\
& 20(17) \\
& 26(22)\end{aligned}$ & $\begin{aligned} 55 & (58) \\
8 & (8) \\
24 & (25) \\
9 & (9)\end{aligned}$ & $\begin{array}{l}38(41) \\
7(8) \\
17(18) \\
30(33)\end{array}$ & $\begin{array}{r}324(56) \\
29(5) \\
140(24) \\
88(15)\end{array}$ & $\begin{array}{l}128(44) \\
25(9) \\
72(25) \\
64(22)\end{array}$ \\
\hline $\begin{array}{l}\text { Homosexual contact } \\
\text { IDU }\end{array}$ & $\begin{aligned} 132(54) \\
1(<1)\end{aligned}$ & $\begin{array}{l}2(1) \\
6(4)\end{array}$ & $\begin{array}{l}51(47) \\
3(3)\end{array}$ & $-(\rightarrow)$ & $\begin{array}{c}535(48) \\
34(3)\end{array}$ & $\begin{array}{r}4(1) \\
26(5)\end{array}$ \\
\hline $\begin{array}{l}\text { Heterosexual contact } \\
\text { with known HIV positive person } \\
\text { with IDU } \\
\text { abroad }\end{array}$ & $\begin{aligned} 105 & (44) \\
3 & (1) \\
7 & (3) \\
31 & (13)\end{aligned}$ & $\begin{aligned} & 149(93) \\
& 7(4) \\
& 10(6) \\
& 32(20)\end{aligned}$ & $\begin{array}{l}50(46) \\
3(3) \\
3(3) \\
14(13)\end{array}$ & $\begin{aligned} 102(94) \\
7(6) \\
5(5) \\
30(28)\end{aligned}$ & $\begin{array}{c}502(45) \\
20(2) \\
9(1) \\
147(13)\end{array}$ & $\begin{array}{c}500(91) \\
43(8) \\
31(6)\end{array}$ \\
\hline $\begin{array}{l}\text { abroad } \\
\text { Blood transfusion }\end{array}$ & $\begin{array}{l}31(13) \\
-(-)\end{array}$ & $32(20)$ & $14(13)$ & $30(28)$ & 147 (13) & $113(21)$ \\
\hline Occupational & -(-) & Z(-) & $\begin{array}{l}-(-) \\
-(-)\end{array}$ & $\begin{array}{r}-(-\overrightarrow{)} \\
2(2)\end{array}$ & $-(-)$ & $-(\rightarrow)$ \\
\hline $\begin{array}{l}\text { Other/undetermined } \\
\text { Ever had STD }\end{array}$ & $4(2)$ & $3(2)$ & $4(4)$ & $2(2)$ & $41(4)$ & $16(3)$ \\
\hline $\begin{array}{l}\text { Screen? Yes } \\
\text { Mean age in years (SE) }\end{array}$ & $\begin{array}{l}89(38) \\
31 \cdot 0(0 \cdot 5)\end{array}$ & $\begin{array}{l}39(25) \\
28 \cdot 3(0 \cdot 4)\end{array}$ & $\begin{array}{l}39(37) \\
28 \cdot 7(0 \cdot 6)\end{array}$ & $\begin{array}{l}31(29) \\
28 \cdot 0(0 \cdot 7)\end{array}$ & $\begin{array}{l}363(33) \\
31 \cdot 1(0 \cdot 2)\end{array}$ & $\begin{array}{l}130(24) \\
28.9(0 \cdot 3)\end{array}$ \\
\hline
\end{tabular}

^Data missing for some subjects. Percentages are based on those subjects with residence or employment recorded. 
Table 2 Self-reported history of STD* among those screened by the investigating physician, by risk for HIV

\begin{tabular}{|c|c|c|c|c|c|c|c|c|}
\hline & \multicolumn{2}{|c|}{$\begin{array}{l}\text { Homosexual } \\
\text { contact }\end{array}$} & \multicolumn{2}{|c|}{$\begin{array}{l}\text { Injecting } \\
\text { drug user }\end{array}$} & \multicolumn{2}{|c|}{$\begin{array}{l}\text { Heterosexual } \\
\text { contact }\end{array}$} & \multicolumn{2}{|c|}{$\begin{array}{l}\text { Otherl } \\
\text { undertermined }\end{array}$} \\
\hline & $\begin{array}{l}\text { Male } \\
\text { No (\%) }\end{array}$ & $\begin{array}{l}\text { Female } \\
\text { No }\end{array}$ & $\begin{array}{l}\text { Male } \\
\text { No }\end{array}$ & $\begin{array}{l}\text { Female } \\
\text { No }\end{array}$ & $\begin{array}{l}\text { Male } \\
\text { No (\%) }\end{array}$ & $\begin{array}{l}\text { Female } \\
\text { No (\%) }\end{array}$ & $\begin{array}{l}\text { Male } \\
\text { No }\end{array}$ & $\begin{array}{l}\text { Female } \\
\text { No }\end{array}$ \\
\hline \multirow{16}{*}{$\begin{array}{l}\text { Total } \\
\text { Ever had STD } \\
\text { screen? Yes } \\
\text { Candida } \\
\text { Chlamydia } \\
\text { Syphilis } \\
\text { Crabs } \\
\text { Gonorrhoea } \\
\text { Trichomonas } \\
\text { Herpes } \\
\text { Warts } \\
\text { Hep B } \\
\text { Other } \\
\text { Non-specific } \\
\text { urethritis } \\
\text { Bacterial vaginosis } \\
\text { Pelvic inflammatory } \\
\text { disease } \\
\text { Epididymitis }\end{array}$} & $132(100)$ & 2 & 1 & 6 & $105(100)$ & $149(100)$ & 4 & 3 \\
\hline & $82(61)$ & - & - & 4 & $34(32)$ & $43(29)$ & 3 & 2 \\
\hline & $5(4)$ & - & - & 1 & $4(4)$ & $29(20)$ & - & 1 \\
\hline & $-(-)$ & - & - & 1 & $3(3)$ & $6(4)$ & - & - \\
\hline & $6(5)$ & - & - & 1 & $-(-)$ & $-(-)$ & - & - \\
\hline & $13(10)$ & - & - & i & $i(1)$ & $1(1)$ & 1 & - \\
\hline & $29(23)$ & - & - & 1 & $4(4)$ & $3(2)$ & - & - \\
\hline & $-(-\rightarrow)$ & - & - & 1 & $-(-)$ & $1(1)$ & - & - \\
\hline & $4(3)$ & - & - & 1 & $2(2)$ & $8(5)$ & - & 1 \\
\hline & $10(7)$ & - & - & - & $7(7)$ & 7 (5) & 1 & - \\
\hline & $18(14)$ & - & - & - & $-(-)$ & $1(1)$ & - & - \\
\hline & & & & & & & & \\
\hline & $18(14)$ & - & - & - & $11(11)$ & $2(1)$ & - & - \\
\hline & $-(-)$ & - & - & - & $-(-)$ & 1 (1) & - & - \\
\hline & $-(-)$ & - & - & - & $-(-)$ & $1(1)$ & - & - \\
\hline & $-(-)$ & - & - & - & $1(1)$ & $-($ - & - & - \\
\hline
\end{tabular}

*People could report more than one previous STD.

declined (108 males/109 females) and those not invited (1113 males/550 females). There is little difference between the three groups with respect to their place of residence, employment status or risk for HIV.

Most people attending the clinic lived in London, approximately half living locally. A relatively high proportion of unemployed people and students attended. Approximately one third of all men and a quarter of all women reported, on the questionnaire, that they had had a previous STD screen.

About half the men reported homosexual contact as their main risk for HIV. Over $90 \%$ of females reported heterosexual contact as their main risk for HIV, with approximately one in five being concerned about sex abroad. Many people reported overseas travel since 1980. Only a small number of men and women reported injecting drug use as their principal risk for HIV which is typical of this clinic population.

Previous STD screening

Subjects were more likely to report having been previously screened for STD when asked directly by the doctor than on the question- naire. Of the males, $47 \%$ told the doctor they had been previously screened for STD compared with $38 \%$ on the questionnaire. The corresponding figures for females was $29 \%$ and $25 \%$. The percentage who reported having been previously screened for STD varied across the risk categories (table 2). All data in Table 2 are based upon data collected during the direct interview with the investigating doctor.

\section{Sexual activity and use of condom}

Of the 132 homosexual men screened for STD, 7\% (9) reported no sexual partners in the last six months, $46 \%$ (61) reported one or two sexual partners in the previous six months while $47 \%$ (62) reported three or more sexual partners in that time period. For the 105 heterosexual males the corresponding percentages were $7 \%$ (7), $70 \%$ (74), $23 \%$ (24) while for the 149 heterosexual females the percentages were $7 \%$ (10), $75 \%$ (112) and $19 \%$ (28).

Reported use of condoms was high. Among the homosexual men $58 \%$ (77) reported always using condoms, $31 \%$ (40) occasionally used them, $11 \%$ (15) never used them. For heterosexual men the corresponding figures

Table 3 Number of STDs detected through screening, by risk for HIV (number of cases detected/number of people screened $\dagger$ )

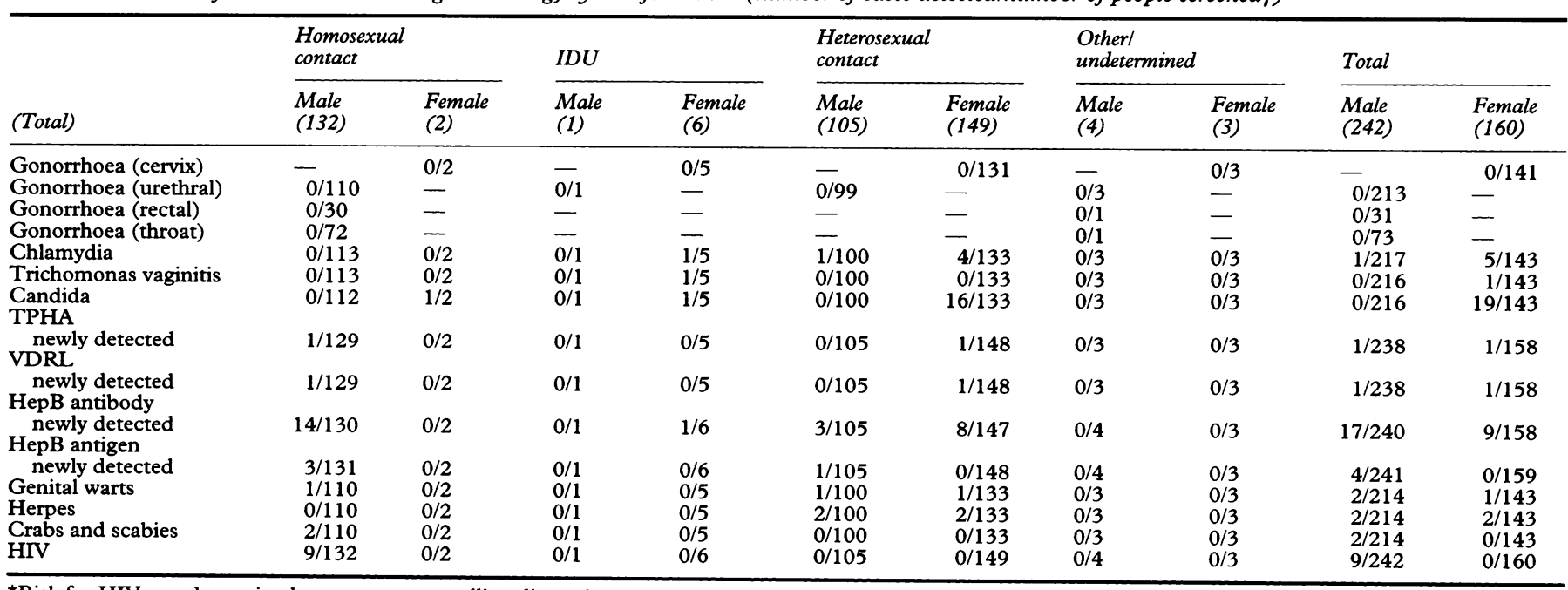


Table 4 Number of people with positive hepatitis B serology, by risk for HIV

\begin{tabular}{|c|c|c|c|c|c|c|c|c|c|c|}
\hline \multirow{2}{*}{$\begin{array}{l}\text { Knowledge of } \\
\text { previous hepatitis } \\
B \text { infection }\end{array}$} & \multicolumn{2}{|c|}{$\begin{array}{l}\text { Homosexual } \\
\text { contact }\end{array}$} & \multicolumn{2}{|l|}{$I D U$} & \multicolumn{2}{|c|}{$\begin{array}{l}\text { Heterosexual } \\
\text { contact }\end{array}$} & \multicolumn{2}{|l|}{ Other } & \multicolumn{2}{|l|}{ Total } \\
\hline & Male & Female & Male & Female & Male & Female & Male & Female & Male & Female \\
\hline Known & 18 & - & - & - & - & 1 & - & - & 18 & 1 \\
\hline Not known & $14^{\star}$ & - & - & 1 & $3+$ & $8 \ddagger$ & - & - & 17 & 9 \\
\hline Total & 32 & - & - & 1 & 3 & 9 & - & - & 35 & 10 \\
\hline
\end{tabular}

*Includes 3 males who were also surface antigen positive

t 1 ex IDU (also surface antigen positive); 1 Kenyan born male; 1 UK born male with no apparent risk factors

$\ddagger 2$ ex partners of IDU; 1 Nigerian and 1 Ugandan born female; 3 UK and 1 Dutch born women with no apparent risk factors.

were $48 \%(50), 38 \%(40)$ and $14 \%(15)$ and for heterosexual women $50 \%$ (74), $32 \%$ (48) and $18 \%(27)$. Some women combined the oral contraceptive pill with the condom.

\section{STD screening}

No cases of gonorrhoea were detected (table 3). Six cases of chlamydia were found (five in females, one male). All were asymptomatic and had not had a previous STD screen. Two cases with positive syphilis serology were found (one homosexual male, one heterosexual female from Ethiopia). Neither reported having had an STD screen in the past.

Three new cases of genital warts were found and four cases of previously undiagnosed herpes, two primary and two secondary episodes.

Of the 133 women who were screened, 19 had candida but not all were symptomatic; 12 had bacterial vaginosis. One woman was referred to a gynaecologist because of a symptomatic cervical polyp while one male was referred back to his general practitioner with a varicocele.

Previously undiagnosed hepatitis B infection was detected in 26 people ( 17 males, 9 females) (tables 3 and 4). Of these, four people were both surface antigen and core antibody positive (three homosexual men and one heterosexual male who subsequently reported injection drug use). They were referred to the genitourinary medicine clinic for follow-up. Of the remaining 22 people who were core antibody positive without prior knowledge of their hepatitis $\mathbf{B}$ infection, 11 were homosexual men, one was an injecting drug user and 10 were heterosexual. Of these 10 heterosexual men and women, three came from areas of high hepatitis B prevalence (Uganda, Nigeria and Kenya), two subsequently gave a history of injecting drug use while the remaining five (four females, one male) reported no apparent risk for hepatitis B.

A further 19 people who were aware of their previous hepatitis $\mathrm{B}$ infection were also core antibody positive (18 homosexual men, one heterosexual female).

Overall, among the 132 homosexual men screened for STD, 24\% (32) were core antibody positive for hepatitis $\mathrm{B}$ infection (table $4)$.

\section{Hepatitis $B$ vaccination}

Of the 132 homosexual men screened for STD, 32 had evidence of previous infection with hepatitis B (table 4); thus vaccination against hepatitis B was not indicated in their case. Among the remaining 100 homosexual men without evidence of previous hepatitis B infection, vaccination status was established for 83 men. Of these, $28 \%$ (23/83) reported having been vaccinated against hepatitis $B$. Some required a booster owing to an incomplete course or passage of time. However, 60 men reported never having been vaccinated against hepatitis B and were referred, mainly to a genitourinary medicine clinic for hepatitis $B$ vaccination.

Among those screened for STD were six health care workers, all of whom had been vaccinated against hepatitis B; one was advised to have a booster vaccination.

\section{HIV infection}

Of those screened for STD, nine males (4\%) and no females $(0 \%)$ were positive for HIV antibodies (table 1). The prevalence of HIV infection in those screened for STD was not significantly different from that seen in those who declined to participate in the study, and among those who were not invited (table 1).

All nine males with newly detected HIV who were screened for STD were homosexual or bisexual. Of the nine men, eight reported having had prior contact with genitourinary services. For the purposes of the study, six had a full screen while three had serological tests only. One man was found to be surface antigen and core antibody positive for hepatitis B without prior knowledge of his infection. A further two men had evidence of previous infection with hepatitis B of which they were aware. No other STDs were found in these men newly diagnosed with HIV infection. Of the six without evidence of prior infection with hepatitis $B$, three had not been vaccinated.

\section{Discussion}

At the Royal Free Hospital NHS Trust Same Day HIV Testing Clinic, the overall prevalence of active STDs in people seeking an HIV test was low. This may be explained by the high reported use of condoms, previous contact with genitourinary medicine services and the fact that this was a largely asymptomatic population seeking only an HIV test. The prevalence of chlamydia infection was low compared with other studies, ${ }^{7-12}$ including those based in general practice. ${ }^{9}$

Current work evaluating the impact of chlamydial infection and the cost effectiveness of screening has shown a variety of predictive factors associated with infection. ${ }^{213}$ These vary in different populations making uniform policies for selective screening difficult to establish. ${ }^{13-15}$

Those people seeking an HIV test who have 
not previously been screened for STD may well be advised to seek such a screen. However, in our study, the prevalence of undetected acute STDs in this subgroup was still low. Nonetheless, a selective screening policy for those who had not had a prior screen would have detected all those found to have chlamydia and positive syphilis serology. There is a debate currently on the cost effectiveness of screening for syphilis. ${ }^{1718}$ Both those with positive syphilis serology in this study were from "high-risk" groups (homosexual man, Ethiopian woman).

This study provides important information on hepatitis $\mathrm{B}$ infection. The high prevalence of hepatitis B reported elsewhere among homosexual men ${ }^{19}$ was also found here, with $24 \%$ of homosexual men having evidence of past infection. In nearly half these cases the person was unaware of his prior infection. However, the number of "low-risk" heterosexuals who also had evidence of past infection can be used as an indicator for the potential spread of HIV in the heterosexual community. ${ }^{3}$

Other studies have shown low levels of hepatitis B vaccination uptake among homosexual men. ${ }^{19}$ In this study only 23 out of 83 men $(28 \%)$ for whom vaccination was indicated had indeed been vaccinated. These results support the need to re-evaluate current vaccination programmes and to extend the availability of hepatitis $B$ vaccination. ${ }^{20}$ While homosexual men and injecting drug users are the highest priority group for vaccination, this study suggests hepatitis B screening and immunisation could be usefully offered to others.

There are limitations to this study. It relied in part on self reported data. Data were incomplete as not all STD tests were acceptable at the time of HIV testing, particularly to homosexual men. A "modified" STD screen was offered as resources were limited; hence rectal and throat swabs were not routinely offered to women. This clinic population is well defined and different results may be expected in other geographic areas with different populations, for example a locality with more injecting drug users. Nonetheless we believe these limitations do not detract from the overall conclusions.

\section{Conclusion}

There is clearly a demand for HIV antibody testing outside the setting of a genitourinary medicine clinic. This demand is likely to increase as testing becomes more widely available and acceptable. Opportunistic screening for STD in this study population has revealed a low prevalence of active STD among those seeking only an HIV antibody test. Thus, concern that a large number of STDs may remain undiagnosed in free standing HIV testing clinics may not be justified. Nonetheless, those seeking an HIV test who have not been screened previously for STD should always be encouraged to have a full STD screen although this could be done at a genitourinary medicine clinic at a later date.

Our findings suggest that all homosexual men seeking an HIV test should be encouraged to establish their hepatitis B status and be vaccinated where appropriate. Health care professionals should not be discouraged from testing for HIV antibodies, whatever the setting, since other issues including immunisation against hepatitis $B$ by vaccination can also be raised.

We thank Rebecca Davidson for Data entry, all the staff involved in the Same Day Testing Clinic, and staff in the Marlborough Clinic, Royal Free Hospital.

This study was funded by the Department of Health.

1 Department of Health. The Health of the Nation: a Strategy for Health in England. London HMSO (1992) cmd 1986 HMSO, London.

2 Taylor-Robinson D. Chlamydia trachomatis and sexually transmitted disease. BMF 1994;308:150-1.
trans

3 From the CDC. Heterosexually acquired AIDS in the United States in 1993. $\mathscr{f} A M A$ 1994;271:975-6.

4 Johnson A, Wadsworth J, Wellings K, Bradshaw Z, Field J. Sexual lifestyles and HIV risk. Nature 1992;360:410-2.

5 Goldberg D, Johnstone F. Universal named testing of pregnant women for HIV. BMF 1993;306:1144-5.

6 Bor R, Lipman M, Elford J, Murray D, Miller R, Griffiths P, et al. HIV Seroprevalence in a London Same Day Testing Clinic. AIDS 1994;8:697-700.

7 Smith JR, Murcloch J, Carrington D, Frew CE, Dougall AJ, Mackinnan $\mathrm{H}$, et al. Prevalence of Chlamydia trachomatis infection in women having cervical smear tests. chomatis infection in
$B M \mathcal{M} 1991 ; 302: 82-4$.

8 Southgate L, Trehame J, Williams R. Detection, treatment and follow up of women with Chlamydia trachomatis infection seeking abortion in inner city general practice. BMF 1989;229:1136-7.

9 Oakeshott P, Hay P. General Practice Update: chlamydia infection in women. $\mathcal{F} R$ Coll Practitioners 1995;45: 615-20.

10 Hart G. Factors associated with genital chlamydial and gonococeal infection in males. Genitourin Med 1993;69: 393-6.

11 Longhurst HJ, Flower N, Thomas BJ, Munday PE, Elder $A$, Constanidan $M$, et al. A simple method for the detection of Chlamydia trachomatis in general practice. $\mathcal{J} R$ tion of Chlamydia trachomatis in general

12 Carlin EM, Russell JM, Sibley K, Boag FC. Evaluating a designated family planning clinic within a genitourinary medicine clinic. Genitourin Med 1995;71:106-8.

13 Tractenberg AI, Washington AE, Halldorson S. A cost based decision analysis for Chlamydia trachomatis screening in Californian family planning clinics. $\mathrm{Br} \mathcal{F} \mathrm{Obs}$ Gynaecol 1988;71:101-8.

14 Thewesson E, van-de Meijen W, Doppenberg H, Mulder $\mathrm{P}$, Wagenfoort J, Stolz E, et al. Screening for cervical Chlamydia trachomatis infection in two Dutch populations. Genitourin Med 1990;66:361-6.

15 Handsfield H, Jasman L, Roberts P, Hanson V, Kothenbeutuel R, Stamm WE, et al. Criteria for selective screening for Chlamydia trachomatis in women attending family planning clinics. $\mathscr{F} A M A$ 1986;255:1730-4

16 Philips RS, Hanaff PA, Holmes MD, Wertheimer A, Aronson $M D$. Chlamydia trachomatis cervical infection in women seeking routine gynaecological care; criteria for selective testing. $A m \mathcal{F} M e d$ 1989;86:15-20.

17 Holland EN, Mahony CPO. Is it time to review antenatal screening for syphilis. $B r \mathcal{F}$ Obstet Gynaecol 1984;308: 1253-4.

18 Nicol A, Moisley C. Antenatal Screening for Syphilis. BMF 1994;308:1253-4.

19 Hart G, Dawson J, Fitzpatrick R, Boulton M, McLean J. Risk behaviour and anti-hepatitis $B$ core prevalence in Risk behaviour and anti-hepatitis $\mathrm{B}$ core prevalence in
clinic and non clinic samples of gay men in England 1991-1992. AIDS 1993;7:863-9.

20 Alter $M$, Hadler S, Margolis $\mathrm{H}$, Alexander J. The changing epidemiology of Hepatitis B in the USA: Need for alternative vaccination strategies. $\mathcal{F} A M A$ 1990;263:1218-22. 